\title{
Konseling Pra Nikah Islam Perannya Bagi Pemilihan Pasangan dan Pernikahan
}

\author{
${ }^{1}$ Rizqi Maulida Amalia, ${ }^{2}$ Muhammad Yudi Ali Akbar \\ ${ }^{1}$ Bimbingan Penyuluhan Islam (konseling), Universitas Al-Azhar Indonesia \\ ${ }^{2}$ Bimbingan Penyuluhan Islam (konseling), Universitas Al-Azhar Indonesia \\ Correspondence email: rizqi.maulida@gmail.com
}

\begin{abstract}
Abstrack: Perkawinan dan keluarga sebagai sebuah institusi sosial mempunyai sistem dan aturan-aturan yang mengatur hubungan di antara anggota keluarga. Aturan atau norma kehidupan berkeluarga berfungsi sebagai benteng bagi keluarga tersebut dalam menghadapi tantangan dan berbagai persoalan dinamika kehidupan. Penguatan pada keluarga dimulai dari pemilihan pasangan sebagaimana Islam mengajarkan. Peran konseling Islam bagi pemilihan pasangan dan kesiapan pernikahan pada penelitian ini ingin melihat bagaimana konseling Islami dapat menjadi bekal dan membimbing dalam pemilihan pasangan sesuai ajaran Islam guna menjadikan keluarga sakinah mawaddah warahmah. Menggunakan metode kualitatif dengan konseling Islam sebagai pendekatannya yang diberikan kepada peserta sekaligus subyek pada penelitian ini. Di gunakan pula kuesioner mate selection sebagai instrumen untuk melihat bagaimana peran konseling yang telah diberikan. Hasil penelitian menunjukkan konseling Islami pra-nikah yang telah dilakukan pada penelitian ini dapat memberikan pemahaman lebih baik kepada para peserta konseling pra nikah. Hal ini ditunjjukkan dengan $84 \%$ peserta inti memiliki skor post test lebih baik daripada sebelum mengikuti rangkaian konseling pra nikah yang berupa ceramah materi tematik, wawancara, diskusi dan sharing.
\end{abstract}

Kata kunci: Konseling Islam; Pemilihan Pasangan; Pernikahan.

\begin{abstract}
Marriage and the family as a social institution has a system and rules that govern the relationships among family members. The rules or norms of family life serves as a fortress for the family in the face of the challenges and issues of dynamics of life. Strengthening families starting from the selection of the couple, according to Islam teaches. Islamic counseling role for election readiness and mate selection on this research would like to see how counseling can be an Islamic provision and guide in the selection of appropriate pair of Islamic teachings in order to make sakinah mawaddah warahmah family. Using qualitative method with Islam as its approach to counseling that is given to participants subject on this research. In use mate selection questionnaire as an instrument to see how the role of counselling has been given. The results showed Islamic pre-marital counseling has been done on this research can provide a better understanding to the participants of the pre marriage counseling. It is shows with $84 \%$ of the core participants have post test score better than before following a series of pre marriage counseling in the form of thematic material of lectures, interviews, discussion and sharing.
\end{abstract}

Keywords: Islamic Counselling; Mate Selection; Marriage.

\section{PENDAHULUAN}

Munculnya fenomena perilaku brutal dan agresif yang dilakukan oleh anak-anak, seperti bullying, tawuran antara kelompok sebaya, penyalahgunaan narkoba, dan lain-lain. Disisi lain melemahnya pondasi hubungan perkawinan yang ditunjukkan oleh adanya peningkatan perceraian yang terdaftar dan tidak terdaftar menunjukkan angka yang signifikan. Fenomena ini tentu akan memberikan dampak kepada anak- 
anak, baik secara langsung ataupun tidak secara langsung.

Komisi Perlindungan Anak Indonesia (KPAI) menyatakan, kekerasan pada anak selalu meningkat setiap tahun. Hasil pemantauan KPAI dari 2011 sampai 2014, terjadi peningkatan yang sifnifikan. "Tahun 2011 terjadi 2178 kasus kekerasan, 2012 ada 3512 kasus, 2013 ada 4311 kasus, 2014 ada 5066 kasus," kata Wakil Ketua KPAI, Maria Advianti kepada Harian Terbit, Minggu (14/6/2015). Dia memaparkan, 5 kasus tertinggi dengan jumlah kasus per bidang dari 2011 hingga april 2015. Pertama, anak berhadapan dengan hukum hingga april 2015 tercatat 6006 kasus. Selanjutnya, kasus pengasuhan 3160 kasus, pendidikan 1764 kasus, kesehatan dan napza 1366 kasus serta pornografi dan cybercrime 1032 kasus.

Kebutuhan untuk memperkuat fondasi perkawinan dalam melaksanakan fungsi keluarga, terutama dalam memelihara dan mendidik anak-anak dengan dasar ajaran Islam tentu merupakan kebutuhan. Keluarga merupakan unit terkecil dalam masyarakat yang memiliki fungsi yang sangat strategis, terutama karena keluarga merupakan lembaga pendidikan pertama dan utama bagi pembentukan dan pembinaan kepribadian. Oleh sebab itu keluarga perlu dibina kesejahteraan, kebahagiaan dan kelestariannya sesuai dengan ajaran agama dan konstitusi. Hanya keluarga yang dilandasi nilainilai agama, kualitas sumber daya manusia yang memiliki kepribadian yang baik yang dapat diwujudkan.

Keluarga yang berkualitas tersebut lahir dari proses ikatan lahir batin melalui pernikahan. Pernikahan yang bukan saja karena dorongan hasrat nafsu seksual semata, akan tetapi didasari nilai luhur mengikuti Sunnah Rosullah;

"Nikah itu adalah sunnahku, barang siapa yang mengingkari sunnahku maka ia tidak termasuk ke dalam golonganku”. (HR. Bukhori Muslim)

Karena dari sinilah akan terbentuk keluarga yang sakinah, mawaddah dan rahmah, tersalurkannya dorongan dan hasrat kasih sayang melalui jiwa manusia. Ikatan lahir batin yang lahir dari sesuatu yang suci yang tidak terlepas dari ketentuan Allah pasti akan memiliki implikasi dan tanggung jawab.

Perkawinan dan keluarga sebagai sebuah institusi sosial tentu mempunyai sistem dan aturan-aturan yang mengatur hubungan di antara anggota keluarga. Aturan atau norma kehidupan berkeluarga berfungsi sebagai benteng bagi keluarga tersebut dalam menghadapi tantangan dan berbagai persoalan dinamika kehidupan keseharian keluarga tersebut. Dengan berumah tangga kehidupan akan lebih terarah, menjamin ketenangan dan ketentraman, terhindarnya seseorang dari perbuatan yang dilarang agama yaitu zina, akan melahirkan keturunan dan tanggung jawab. Walaupun demikian, berbagai kajian telah menunjukkan berbagai manfaat dari perkawinan (Olson \& Olson, 2000), antara lain:

1. Orang yang menikah memiliki gaya hidup yang lebih sehat Orang yang menikah cenderung menghindari perilaku yang berbahaya daripada lajang, bercerai, atau duda. Misalnya orang yang menikah lebih sedikit memiliki masalah minuman keras, yang sering kali terkait dengan masalah kecelakaan, konflik antarpribadi, dan depresi.

2. Orang yang menikah hidup lebih lama. Hal ini dapat terjadi kare-na merekamemiliki dukungan emosi dari pasangan dan akses terhadap sumber daya ekonomi.

3. Orang yang menikah memiliki kepuasan relasi seksual yang le-bih baik. Sekitar 54\% dari laki-laki yang menikah dan $43 \%$ dari perempuan yang menikah merasa sangat puas dengan relasi sek-sualnya. Angka ini lebih tinggi bila dibandingkan dengan pelaku kohabitasi, dengan angka 44\% laki-laki dan $35 \%$ perempuan. Angka-angka tersebut merupakan temuan di Amerika, sayangnya angka-angka yang berlaku di Indonesia belum terungkap.

4. Orang yang menikah lebih sejahtera secara ekonomi. Orang yang menikah dapat menggabungkan pendapatannya sehingga dapat meningkatkan kemampuan ekonominya.

5. Anak-anak pada umumnya tumbuh lebih baik bila diasuh oleh orang tua lengkap. Anak-anak dengan kedua orang tua yang ting-gal serumah cenderung lebih baik secara emosi dan akademik. Sebagai remaja, mereka lebih sedikit yang mengalami hamil se-belum menikah. Anak-anak dapat memperoleh perhatian yang lebih dari kedua orang tua, misalnya dalam hal pendampingan, bantuan untuk menyelesaikan tugas sekolah, dan kualitas keber-samaan.

Keberadaan Dai-Konselor dalam masyarakat memperoleh tempat tersendiri, karena disamping merupakan da'i juga 
mempunyai keahlian khusus dalam bidang konseling pada umumnya. Dalam dinamika kehidupan sosial di masyarakat Da'i-Konselor memiliki peran cukup penting sebagai tokoh panutan, pembimbing masyarakat dan penyambung tugas agama. Dengan demikian ia tidak hanya sebagai yang mengerti tentang akademisi, akan tetapi mampu berperan sebagai da' $i$ yang mampu berperan aktif dan kreatif melakukan seleksi atas nilai-nilai dan sikap-sikap positif yang seharusnya dikembangkan dalam masyarakat. Pertanyaan pokok penelitian ini adalah : "bagaimana kegiatan konseling yang dilakukan ditengah masyarakat khususnya pada subjek yang sedang pada tahapan pra-nikah".

\section{METODE}

Sebelum memberikan post test dengan menggunakan 9mate selection scale test yang telah diadaptasi (townsend: 1993), peserta terlebih dahulu diberikan pertanyaan awal dan informasi awal mengenai konseling pra-nikah. Jumlah peserta yang bersedia adalah berdasarkan hasil seleksi dari awal pelaksanaan dan kesediaan untuk mengikuti rangkaian acara konseling. Penjelasan jumlah peserta sebagai berikut:

Tabel 1 bluprint 9 mate selection scale (adaptasi townsend, 1993).

\begin{tabular}{ccc}
\hline Dimensi & Favorable & Unfavorable \\
Sosial Ekonomi & 2,4 & $1,3,5$ \\
Dukungan & 6,7 & \\
terhadap & & \\
pasangan & & 8,10 \\
Daya tarik fisik & 9 & \\
\hline
\end{tabular}

Setelah di lakukan screening awal, maka berjumlah 19 peserta yang bersedia mengikuti rangkaian konseling dan memenuhi kriteria sebagai peserta. Selanjutnya 19 peserta inilah yang menjadi peserta inti konseling pra-nikah pada penelitian ini. Rangkaian jadwal dan materi konseling yang telah diberikan terdapat pada tabel di bawah ini:

Tabel 2. Pertemuan kegiatan Konseling

\begin{tabular}{|c|c|c|c|}
\hline No & $\begin{array}{c}\text { Pertemuan/Jad } \\
\text { wal }\end{array}$ & Materi & keterangan \\
\hline 1 & 27 April 2017 & $\begin{array}{l}\text { 1. Pre test dengan } \\
\text { kuesioner '9mate } \\
\text { selection' } \\
\text { 2. Wawancara awal }\end{array}$ & terlampir \\
\hline 2 & 6 Mei 2017 & Memilih Pasangan Hidup & terlampir \\
\hline 3 & 10 Mei 2017 & $\begin{array}{l}\text { Persiapan Ruhiyah menuju } \\
\text { Pernikahan }\end{array}$ & terlampir \\
\hline 4 & 18 Mei 2017 & $\begin{array}{l}\text { Fiqih Munakahat (memilih } \\
\text { pasangan, khitbah, mahar, } \\
\text { walimah, talaq, ruju) }\end{array}$ & terlampir \\
\hline 5 & 19 Mei 2017 & Manajemen Rumah Tangga & terlampir \\
\hline 6 & 8 Juni 2017 & $\begin{array}{lll}\text { Hukum } & \text { Pernikahan } & \text { di } \\
\text { Indonesia } & & \\
\end{array}$ & terlampir \\
\hline 7 & 11 Juni 2017 & Post Test dan sharing & terlampir \\
\hline
\end{tabular}




\section{HASIL DAN PEMBAHASAN}

Seluruh pertemuan berjumlah 7X dengan materi bahasan sebagaimana terdapat pada tabel. Materi disampaikan berupa metode ceramah dan diskusi kecuali saat pre dan post test maka di lakukan dialog satu per satu. Ceramah dan diskusi dilakukan pada pertemuan mata kuliah Pendidikan Agama Islam. Hanya 19 peserta saja yang merupakan peserta inti dan diikut sertakan pada penelitian ini, selebihnya sebagai peserta mata kuliah pada umumnya. Setelah 7 Pertemuan dilakukan ceramah, diskusi dan sharing, kemudian pada tahap akhir dilakukan post test sebagaimana pada tahapan awal. Hasil dari pra dan post test peserta inti konseling adalah sebagai berikut;

Tabel 3. Hasil Pre dan Post 9mate selection test

\begin{tabular}{lrrr}
\hline \multirow{2}{*}{ peserta } & \multirow{2}{*}{ Jenis Kelamin } & \multicolumn{2}{c}{ Hasil } \\
\cline { 3 - 4 } & Laki-laki & 41 & Post test \\
\hline 1 & Laki-Laki & 36 & 32 \\
\hline 2 & Perempuan & 34 & 37 \\
\hline 3 & Perempuan & 30 & 31 \\
\hline 4 & Perempuan & 32 & 32 \\
\hline 5 & Perempuan & 33 & 36 \\
\hline 6 & Perempuan & 25 & 34 \\
\hline 7 & Perempuan & 32 & 30 \\
\hline 8 & Perempuan & 37 & 33 \\
\hline 9 & Perempuan & 27 & 38 \\
\hline 10 & Laki-laki & 32 & 34 \\
\hline 11 & Perempuan & 28 & 36 \\
\hline 12 & Perempuan & 39 & 31 \\
\hline 13 & Perempuan & 28 & 42 \\
\hline 14 & Perempuan & 32 & 33 \\
\hline 15 & Perempuan & 31 & 37 \\
\hline 16 & Perempuan & 32 & 32 \\
\hline 17 & Perempuan & 31 & 34 \\
\hline 18 & Laki-laki & 32 & 32 \\
\hline 19 & & & 34 \\
\hline
\end{tabular}

Dari tabel tentang hasil olah pra dan post test konseling pra nikah menggunakan skala '9 mate selection' yang telah diadaptasi, diperoleh hasil bahwa jumlah peserta inti sebanyak 19 mahasiswa dengan jumlah perempuan sebanyak 15 orang dan laki-laki sebanyak 4 orang. Berdasarkan hasil pra dan post test, ada 3 peserta yang skor post test nya lebih kecil dibandingkan pre test nya ( yaitu peserta 1 , 2 dan 5). Kemudian ada $84 \%$ dari total peserta inti yang memiliki skor hasil post test lebih baik di bandingkan skor hasil pre test sebelumnya.

Konseling yang telah dilakukan dalam penelitian ini dengan pembahasan mengenai pernikahan dan keluarga. Dilakukan dengan model ceramah materi dan diskusi atau sharing. Rangkaian kegiatan konseling yang telah dilakukan, kemudian diperkuat efektifitasnya dengan menggunakan kuesioner sederhana untuk melihat seberapa pemahaman para peserta inti konseling terhadap konsep keluarga dalam Islam khususnya tentang pemilihan pasangan.

Pada awal uji pelaksanaan konseling, dalam menentukan peserta inti, dari 70 jumlah total calon peserta hanya 19 yang memenuhi kriteria dan bersedia untuk mengikuti rangkaian konseling. Beberapa di antara nya gugur karena tidak memenuhi kriteria yaitu; telah berkeluarga, sudah pernah mengikuti seminar/kursus pra 
nikah dan tidak bersedia untuk di wawancara serta mengikuti rangkaian konseling.

Hasil menunjukkan bahwa ada $84 \%$ dari total peserta inti yang memiliki skor post test lebih baik dan lebih tinggi dibandingkan sebelumnya. Post test ini dilakukan setelah peserta melalui serangkaian kegiatan konseling pra nikah Islam yang berjumlah $7 \mathrm{X}$ pertemuan

Dari tabel data wawancara terhadap peserta inti konseling pra-nikah Islam, terdapat beragam jawaban. Mengenai kriteria pemilihan pasangan berdasarkan usia, suku, agama, kewarganegaraan, status pernikahan, pendapatan, pekerjaan. Wawancara dilakukan pada awal rangkaian kegiatan konseling pra-nikah islam bersamaan dengan pengisian kuesioner. Berdasarkan jawaban dari peserta, masih terdapat kecenderungan tertentu dalam memilih pasangan dan berkeluarga. Sebagai contoh, peserta no. 19 yang memilih pasangan dengan tidak mempermasalahkan agama sebagai kriteria (berbeda atau sama) tidak masalah. Seluruh peserta (kecuali Peserta no. 5, 11, 14) memilih pasangan masih mempertimbangkan suku asal atau keluarga dan kecenderungan memilih suku tertentu.

Hasil wawancara awal memperlihatkan dalam kriteria pemilihan pasangan, usia, suku, status pernikahan, pendapatan dan pekerjaan menjadi kriteria utama dalam pemilihan. Sebagai contoh, peserta dengan berlatar belakang suku tertentu akan memilih pasangan dengan suku yang sama atau beberapa suku yang berdekatan secara adat istiadat. Dalam hal pendapatan, peserta mayoritas menjawab antara $\mathrm{Rp}$ 16.000.000 - Rp 25.000.000 dengan pendidikan minimal Strata satu hingga strata 3 dan pekerjaan sebagai wiraswasta, profesional dan TNI/POLRI.

Dengan wawancara awal tersebut, tergambar bagaimana pemahaman dan kecenderungan pemilihan pasangan dari peserta konseling pra nikah Islam pada penelitian ini. Terutama bagi kriteria yang tidak sesuai dengan ajaran Islam, misal nya pengkhususan bagi suku tertentu atau berbeda agama, hal ini yang menjadi bahan kajian mendalam konseling pra Nikah Islam, agar setelah rangkaian acara berlangsung, peserta dapat memahami dan mempraktekan pemilihan pasangan dan pernikahan sesuai ajaran Islam sebagaimana dalam Qur'an dan as Sunnah.

\section{SIMPULAN DAN SARAN}

Hasil penelitian menunjukkan (1) konseling Islami pra-nikah yang telah dilakukan pada penelitian ini dapat memberikan pemahaman lebih baik kepada para peserta konseling pra nikah. Hal ini ditunjjukkan dengan $84 \%$ peserta inti memiliki skor post test lebih baik daripada sebelum mengikuti rangkaian konseling pra nikah yang berupa ceramha materi tematik, wawancara, diskusi dan sharing. (2) Masih ada ketertutupan diri dari calon peserta konseling ini sehingga hanya 19 orang yang bersedia dan memenuhi kriteria sebagai peserta inti, peserta tidak menginginkan untuk di wawancara dan mengikuti rangkaian kegiatan. (3) Perlu adanya kegiatan intensif dan lebih mendalam mengenai konseling pra nikah Islam dengan cakupan peserta lebih luas serta durasi yang lebih lama agar lebih intensif. (4) Penelitian selanjutnya di harapkan dapat lebih luas cakupan materi dan peserta nya dan dilakukan dengan longitudinal research ( pra nikah dan pasca nikah).

\section{DAFTAR RUJUKAN}

De Genova. (2008). Intimate Relationship, Marriage and Families. New York: Mc Graw Hill

Janis, Irving I, Mann, Leon. (1979). Decision Making: A Psychological Analysis of Conflict, Choice and Commitment. New York : The Free Press

Kartono, Kartini. (1992). Psikologi Wanita, Mengenal Gadis Remaja dan Wanita Dewasa. Bandung : Mandar Maju

Moleong, L. J. (2002). Metodologi penelitian kualitatif. Bandung : PT Remaja Rosdakarya

Papalia, D. E., et al. (2009). Human Development (Psikologi Perkembangan). Jakarta : Kencana

Poerwandari, E. Kristi. (2007). Pendekatan Kualitatif untuk Penelitian Perilaku Manusia. Jakarta : Lembaga Pengembangan Sarana Pengukuran dan Pendidikan Psikologi (LPSP3) Universitas Indonesia

Santrock, J.W. (2002). Life-Span Development : Perkembangan Masa Hidup Jilid II. Alih bahasa oleh Achmad Chusairi dan Juda Damanik. Jakarta : Erlangga 
Walgito. Bimo. (2002). Bimbingan dan Konseling Perkawinan, Yogyakarta: Andi

Wisnuwardhani, Dian \& Mashoedi, Sri Fatmawati. (2012). Hubungan Interpersonal. Jakarta : Salemba Humanika

Ari Kusumawati (2009). Hubungan Faktor Sosial dengan Sikap Remaja dalam Mengambil Keputusan Menikah Muda di Pacitan. Skripsi. UMS.

Octavia, Devi. Hubungan Penyesuaian diri remaja yang menikah muda. eJournal Psikologi, 2014, 2 (1): 115-122. ISSN 0000-0000, ejournal.psikologi.fisipunmul.ac.id.
Milda Itares . Fenomena Pernikah Usia Muda di Pontianak. (2015). Socioloque, Jurnal S1 Sosiologi Vol. 3 No 1 Edisi Maret 2015. http://jumafis.untan.ac.id

Ahmad Mubarok, Teori dan Kasus, cet I (Jakarta: Bina Rena Pariwara, 2000), hal 4-5 22

Syaiful Akhyar Lubis, (2007). Konseling Islami. Yogyakarta: eLSAQ Press

Erhamwilda. (2008) Konseling Islami, (Yogyakarta: graha ilmu

Thohari Musnamar. (1992) Dasar-Dasar Konseptual Bimbingan dan Konseling Islam. Yogyakarta: UII Press 